\title{
Judicialização da saúde, acesso à justiça e a efetividade do direito à saúde
}

I ${ }^{1}$ Miriam Ventura, ${ }^{2}$ Luciana Simas,

${ }^{3}$ Vera Lúcia Edais Pepe, ${ }^{4}$ Fermin Roland Schramm |

Resumo: Este artigo busca analisar os vínculos entre acesso à justiça e a efetividade de um dos aspectos do direito à saúde: o acesso aos medicamentos. Inicialmente, apresenta os desafios e as dificuldades na conceituação de saúde e do direito à saúde. Em seguida, analisa processos judiciais individuais que reivindicam dos entes públicos o fornecimento de medicamentos, no período de junho de 2007 a julho de 2008, no Tribunal de Justiça do Estado do Rio de Janeiro. Constata-se que a prescrição médica individual, a hipossuficiência econômica e a urgência dos demandantes ao acesso aos medicamentos são os principais respaldos das decisóes judiciais analisadas, que determinam o fornecimento de medicamento conforme requerido pelos autores. Conclui-se que a efetividade do direito à saúde requer um conjunto de respostas políticas e ações governamentais mais amplas, e não meramente formais e restritas às ordens judiciais. As demandas judiciais não podem ser consideradas como principal instrumento deliberativo na gestão da assistência farmacêutica no SUS, mas admitidas como um elemento importante na tomada de decisão dos gestores e, muitas vezes, na melhoria do acesso aos medicamentos no âmbito do SUS. No contexto democrático brasileiro, a judicialização pode expressar reivindicações e modos de atuação legítimos de cidadãos e de instituiçōes. O principal desafio é formular estratégias políticas e sociais orquestradas com outros mecanismos e instrumentos de garantia democrática, que aperfeiçoem os sistemas de saúde e de justiça com vistas à efetividade do direito à saúde.

> Palavras-chave: Direito à saúde. Assistência Farmacêutica. Sistema de Justiça. Bioética.

\author{
${ }^{1}$ Mestre e doutoranda em \\ Saúde Pública na Escola \\ Nacional de Saúde Pública \\ Sérgio Arouca, Fundação \\ Oswaldo Cruz; consultora \\ jurídica. Endereço eletrônico: \\ venturaadv@oi.com.br \\ ${ }^{2}$ Mestre em Direito e Sociologia \\ pelo PPGSD/UFF, consultora \\ jurídica. Endereço eletrônico: \\ luciana.simas@ig.com.br \\ 3 Doutora em Saúde Pública; \\ pesquisadora do Departamento \\ de Administração e \\ Planejamento em Saúde, Escola \\ Nacional de Saúde Pública \\ Sergio Arouca, Fundação \\ Oswaldo Cruz. Endereço \\ eletrônico: verapepe@ensp. \\ fiocruz.br \\ ${ }^{4}$ Doutor em Saúde Pública \\ com Pós-Doutorado em \\ Bioética; pesquisador titular \\ do Departamento de Ciências \\ Sociais, Escola Nacional de \\ Saúde Pública Sérgio Arouca, \\ Fundação Oswaldo Cruz. \\ Consultor de bioética do \\ Instituto Nacional do Câncer. \\ Endereço eletrônico: roland@ \\ ensp.fiocruz.br
}

Recebido em: 27/01/2010. Aprovado em: 22/02/2010. 
No contexto democrático contemporâneo, o fenômeno da judicialização da saúde expressa reivindicações e modos de atuação legítimos de cidadãos e instituições, para a garantia e promoção dos direitos de cidadania amplamente afirmados nas leis internacionais e nacionais. O fenômeno envolve aspectos políticos, sociais, éticos e sanitários, que vão muito além de seu componente jurídico e de gestão de serviços públicos.

Os vínculos entre Direito e Saúde Coletiva intensificaram-se nas últimas décadas, com a consolidação de jurisprudências e intervençôes do Poder Judiciário na gestão de saúde, inclusive no que se refere à Assistência Farmacêutica (AF). O processo judicial, individual e coletivo, contra os Poderes Públicos, teve início na década de 90, com as reivindicações das pessoas vivendo com HIV/Aids para medicamentos e procedimentos médicos. As reivindicações fundamentam-se no direito constitucional à saúde, que inclui o dever estatal de prestar assistência à saúde individual, de forma integral, universal e gratuita, no Sistema Único de Saúde (SUS), sob a responsabilidade conjunta da União Federal, estados e municípios. A ampla estratégia de advocacia empreendida pelas organizaçóes não-governamentais (ONGs), em todo Brasil, resultou numa jurisprudência favorável à responsabilização dos entes federativos no cumprimento imediato desta prestação estatal (RIOS, 2003; VENTURA, 2003; SCHEFFER et al., 2005), e em avanços nas políticas públicas de saúde às pessoas com HIV/Aids, em especial o acesso universal e gratuito aos medicamentos antirretrovirais (LOYOLA, 2008). De fato, parece que este segmento conseguiu estabelecer uma relação positiva entre acesso à justiça e a efetividade do direito à saúde.

Os avanços das políticas públicas na assistência às pessoas com HIV/Aids parecem ter animado outros movimentos sociais organizados e a população em geral, pois, nas últimas décadas, pode-se constatar que a reivindicação judicial passa a ser largamente utilizada como mecanismo de garantia de direitos e ampliação de políticas públicas, ampliando, inclusive, a atuação do Ministério Público neste âmbito (VIANNA; BURGOS, 2005). Mas também, constatase a inclusão do recurso judicial no "itinerário terapêutico" (GERHARDT, 2006) de milhares de cidadãos, que de forma individual buscam garantir o fornecimento de insumos e procedimentos de saúde para suas necessidades individuais, por essa via. 
A demanda judicial individualizada relacionada a procedimentos e insumos

de saúde contra entes públicos teve um crescimento exponencial nos últimos anos. É interessante notar que a intensidade da demanda judicial das pessoas com HIV/Aids sofreu acentuada redução, se comparada à de outras doenças (MESSEDER et al., 2005). Observa-se que houve avanços nas políticas e ações públicas de assistência farmacêuticas; no entanto, ainda há dificuldades de acesso da população aos medicamentos necessários à assistência integral à saúde. No Brasil, estimou-se que, em 2000, 70 milhões de pessoas não tinham acesso a medicamentos, o que correspondia a aproximadamente $41 \%$ da população brasileira (VIEIRA; ZUCCHI, 2007). Além disso, a despesa com medicamentos representa a de maior peso no gasto total das famílias com saúde, impactando no orçamento, principalmente entre os mais pobres - o que a caracteriza como altamente regressiva (IBGE, 1998; IBGE, 2004; SZWARCWALD et al., 2004). A "Pesquisa Mundial da Saúde" (PMS) no Brasil de 2003 (SZWARCWALD et al., 2004) e a "Avaliação da Assistência Farmacêutica no Brasil", realizada em 2004 (BRASIL/MS/OPAS, 2005), apontam para um acesso - público e privado - de, respectivamente, $87,0 \%$ e $89,6 \%$ dos medicamentos prescritos na última consulta. No entanto, em ambos os estudos, a falta de recurso financeiro constou como a principal alegação entre os que não conseguiram obter seus medicamentos (55,0\% e 62,8\%, respectivamente).

De maneira geral, os estudos sobre a judicialização da saúde enfatizam mais fortemente os efeitos negativos deste tipo de demanda na governabilidade e gestão das políticas e ações de saúde. Uma das principais justificativas é que este tipo de intervenção no SUS aprofundaria as iniquidades no acesso à saúde, privilegiando determinado segmento e indivíduos, com maior poder de reivindicação, em detrimento de outros, na medida em que necessidades individuais ou de grupos determinados seriam atendidas em prejuízo a necessidades de outros grupos e indivíduos (BARATA; CHIEFFI, 2009; MARQUES; DALLARI, 2007; VIEIRA; ZUCCHI, 2007). Outros estudos apontam, com maior ênfase, as deficiências e insuficiências do sistema de saúde e do sistema judiciário brasileiro para responder de forma satisfatória às novas e crescentes demandas de saúde, num contexto normativo que atribui obrigações legais amplas ao Estado brasileiro (MESSEDER et al., 2005; BORGES, 2007; ROMERO, 2008; SANT'ANA, 2009). 
Um tema persistente que perpassa as discussões refere-se ao marketing comercial e/ou lobby exercido pela indústria e comércio farmacêutico, junto a segmentos sociais (pesquisadores, pacientes, médicos) e governamentais, para incorporação de seus produtos, o que poderia estar exercendo papel importante no sentido de estimular a demanda judicial para incorporação de novos medicamentos. Também se chama atenção para a forte dependência dos estados nacionais das indústrias farmacêuticas, tanto no desenvolvimento das pesquisas clínicas como em relação ao custo da incorporação das novas tecnologias nos sistemas de saúde. Nesse sentido, a equidade no acesso à saúde e a discussão sobre os efeitos da judicialização da saúde são relacionadas às questôes de alocação de recursos públicos para pesquisa e assistência; do uso racional das novidades tecnológicas e científicas na prática médica, nos sistemas de saúde e também à propriedade intelectual. Destaca-se, neste âmbito, a necessidade de se estabelecer um padrão de assistência e/ou critérios para a incorporação e o acesso aos procedimentos e insumos na assistência pública à saúde que conduzam à equidade e integralidade no acesso a este bem de saúde, tornando a assistência farmacêutica mais efetiva.

Pode-se dizer, portanto, que a ampliação da atuação do sistema de justiça no acesso à assistência à saúde tem repercussóes sobre a gestão, influenciando na tomada de decisão dos profissionais envolvidos, e que, ao menos em parte, decorre das deficiências da própria administração pública. Alguns estudiosos apontam que a relação estabelecida entre acesso à justiça e à saúde pode ter "um efeito benéfico na responsabilização do Estado em desenvolver procedimentos adequados de incorporação, compra e distribuição de procedimentos terapêuticos pela rede pública" (BAPTISTA, 2009, p. 829). Já os efeitos negativos desta atuação podem estar relacionados à alta e persistente demanda judicial, combinada com respostas automáticas e insatisfatórias sem uma devida e cuidadosa análise crítica da demanda, pelos atores envolvidos. A combinação desses elementos pode causar um tipo de "disfunção nos sistemas" (BARROSO, 2009), com "o risco de se desenvolver a via judicial como principal meio para se garantir o acesso ao medicamento" (BAPTISTA, 2009, p. 836) e, nesse sentido, causar prejuízos significativos à efetividade (individual e coletiva) do direito à saúde, com violação de princípios éticos e legais importantes, como o acesso igualitário e a integridade física e saúde do demandante.

O presente artigo busca problematizar esta relação entre o acesso à justiça e a efetividade de um dos aspectos do direito à saúde: o acesso aos medicamentos, 
numa perspectiva bioética e sanitária, no ambiente Judiciário. A discussão é iniciada com a apresentação das dificuldades mais relevantes na compreensão do conceito de saúde e do direito à saúde, que influenciam a efetividade deste direito. A seguir, são apresentados os dados resultantes da pesquisa em desenvolvimento no Rio de Janeiro, sobre "Judicialização e Saúde Pública: proposta de análise e monitoramento das demandas judiciais individuais para o acesso a medicamentos", que tem como objetivo a construção de um modelo de monitoramento da demanda judicial individual para fornecimento de medicamentos, que sirva como ferramenta para a gestão de saúde e judicial (edital MCT/CNPq/MS-SCTIEDECIT33/2007). Ao final, se busca entrelaçar o debate sobre acesso à saúde com o tema do acesso à Justiça, a partir das consideraçôes desenvolvidas.

\section{Da saúde ao direito à saúde}

Em sentido amplo e contemporâneo, saúde é sobretudo uma questão de cidadania e de justiça social, e não um mero estado biológico independente do nosso status social e individual. Os principais documentos nacionais e internacionais acerca do tema consagram a caracterização de saúde como um completo estado de bem-estar, e não a mera ausência de doenças, incorporando também a concepção de que a situação de saúde é determinada pelas condições de vida e de trabalho dos indivíduos; pela conjuntura social, econômica, política e cultural de determinado país (SCLIAR, 2007); por aspectos legais e institucionais relativos à organização dos sistemas de saúde; e por valores individuais e coletivos sobre como viver bem (AYRES, 2007).

Esta definição ampla e positiva de saúde responde às principais críticas acerca das perspectivas meramente curativas das práticas e políticas de saúde, que dão ênfase ao uso de tecnologia para o diagnóstico, à restrição da terapêutica à prescrição medicamentosa, à "naturalização" e produção de "necessidades de saúde" que se transformam em "demandas de saúde" (CAMARGO JR, 2007, p. 64-65). $\mathrm{O}$ aspecto negativo desta perspectiva reducionista é um acentuado processo de reificação da noção de doença que desloca "o indivíduo doente do foco do olhar médico", dando centralidade à "doença-coisa”, tornada uma entidade "natural”, e reduzindo, portanto, as demandas de saúde a demandas por bens de consumo que integram o processo curativo (CAMARGO JR, 2007, p. 64-65). Assim sendo, ter acesso às tecnologias de saúde pode representar, por exemplo, o principal ou mesmo 
o único meio considerado eficiente e legítimo para o indivíduo alcançar esse bemestar/bem-viver, que é a saúde. Conclui o autor:

pode-se dizer que uma peça fundamental das estratégias de legitimação e expansão de oportunidades de intervenção dos vários agentes do CMI [complexo médico-industrial] - incluindo-se os alternativos - é o estabelecimento de "necessidades de saúde", que, apesar de constantemente em expansão, são apresentadas como naturalmente existentes (CAMARGO JR, 2007, p. 70)

Importante destacar que as críticas a esse modelo reducionista não negam a importância de se disponibilizar um conjunto de técnicas, equipamentos e insumos (recursos técnicos e científicos) para atender às questôes de saúde; nem tampouco desconsideram o dever do gestor de saúde identificar e resolver as demandas de saúde, determinar prioridades e alocar recursos para tal (CAMARGO JR, 2007, p. 66). Somente destacam que a compreensão do conceito de saúde implica o desenvolvimento de políticas e ações mais amplas, que assegurem bem-estar a todos (SCLIAR, 2007). Outras críticas alertam para a necessidade de se construir novas instrumentalidades dos conceitos de saúde e doença, capazes de

resgatar o lugar da racionalidade prática como origem e destino de qualquer instrumentalidade nessa área [...] que envolve a construção compartilhada de nossas ideias de bem viver e de um modo conveniente de buscar realizá-las na nossa vida em comum. (AYRES, 2007, p. 50-51).

As dificuldades apontadas na compreensão de saúde e de doença são basicamente de três ordens: a indefinição conceitual, o reducionismo biológico da biomedicina e a reificação dessas noções, que se expressam claramente no desenho das políticas públicas de saúde (CAMARGO JR, 2007, p. 64-65), das leis e jurisprudências relacionadas ao tema.

O direito à saúde é reconhecido, em leis nacionais e internacionais, como um direito fundamental que deve ser garantido pelos Estados aos seus cidadãos, por meio de políticas e ações públicas que permitam o acesso de todos aos meios adequados para o seu bem-estar. $\mathrm{O}$ direito à saúde implica, também, prestações positivas, incluindo a disponibilização de serviços e insumos de assistência à saúde, e tendo, portanto, a natureza de um direito social, que comporta uma dimensão individual e outra coletiva em sua realização. A trajetória do reconhecimento do direito à saúde como relativo à dignidade humana e, consequentemente, sua incorporação nas leis, políticas públicas e jurisprudências, espelham as tensões e percepções sobre as definições de saúde e doença, de como alcançar este Estado de bem-estar, e quais os direitos e responsabilidades dos cidadãos e dos Estados. 
Uma primeira dificuldade ética na identificação da saúde como um bem a ser tutelado pelo Direito é estabelecer critérios universalizáveis para definir este bem, ou mesmo os benefícios ou as necessidades para determinada pessoa ou comunidade, considerando que dependem de uma valoração específica, nos diversos contextos morais e sociais, e, em especial, nas sociedades pluralistas (ENGELHARDT JR., 1998).

Outra dificuldade é a escolha dos meios para o alcance da saúde, considerando os aspectos anteriormente abordados de reificação da saúde e da doença, bem como a força simbólica desse processo de reificação, na percepção das pessoas e nas práticas de saúde (LEFÈVRE, 1987). Atualmente, há um leque amplo de recursos científicos e tecnológicos para a intervenção na saúde e na vida humana, e o acesso a essas novidades é visto como instrumento indispensável para a ampliação da liberdade pessoal e da melhoria das condições de vida, no sentido em que oferecem alternativas para prevenir doenças, superar deficiências orgânicas e desconfortos com seu próprio corpo. Porém, há ainda muitas dúvidas sobre se o uso dessas novas alternativas pode ser positivo ou negativo, seja no sentido restrito da proteção à integridade física e psíquica dos indivíduos, como no aspecto mais amplo de respeito da dignidade da pessoa humana. Neste sentido, a problemática central trazida para o Direito e a Saúde - que se expressa no fenômeno da judicialização da saúde - é a de como o Estado, no âmbito dos Poderes Executivo, Legislativo ou Judiciário, deve proteger as pessoas dos riscos das novidades oferecidas pelo "mercado de saúde", que, não raramente, cria "necessidades" para "vender" soluções. E, ao mesmo tempo, fazer cumprir com seu dever de assistência, promovendo o acesso aos avanços biotecnocientíficos que de fato podem ser benéficos ao processo terapêutico e ao bem-estar das pessoas, de forma igualitária e sem discriminação de qualquer espécie.

Uma terceira dificuldade na passagem da saúde para o direito à saúde é que a realização do direito à saúde comporta a satisfação de uma dimensão individual ou privada, que exige respeito às subjetividades, aos direitos e liberdades pessoais; e uma dimensão coletiva, que requer assegurar esse bemestar individual a todos, a um custo aceitável para a sociedade $\mathrm{Na}$ conjugação de interesses individuais e sociais e no cumprimento dos deveres do Estado de proteção da saúde de todos e de cada indivíduo, podem ser necessárias restrições à liberdade de alguns, em prol do bem-estar coletivo ou para o alcance de um 
determinado bem ou interesse social. A questão central nesta conjugação é a legitimidade da norma que restringe a liberdade individual, correlacionada com a ideia do que se entende por lei justa.

\section{O desafio da efetividade do direito à saúde e a judicialização da saúde no Brasil}

Norberto Bobbio, ao falar sobre o "Presente e futuro dos direitos do homem", afirma que o problema atual em relação a esses direitos não é tanto o de justificá-los, mas o de protegê-los. Não nega que exista uma crise dos fundamentos filosóficos desses direitos, e que devemos reconhecê-la, porém indica que nossa tarefa, urgente e atual, "é muito mais modesta, embora também mais difícil", que é a "de buscar, em cada caso concreto, os vários fundamentos possíveis". Este empreendimento deve ser acompanhado "pelo estudo das condiçōes, dos meios e das situaçōes nas quais este ou aquele direito pode ser realizado", não se dissociando o problema dos fins do problema dos meios. Ademais, buscando identificar "qual é o modo mais seguro para garanti-los, e para impedir que, apesar das solenes declaraçóes, eles sejam continuamente violados" (BOBBIO, 1992, p. 24-25).

$\mathrm{O}$ direito à saúde é reconhecido formalmente como um direito humano fundamental à preservação da vida e dignidade humana. Pode-se dizer que, nesse aspecto, há absoluta concordância entre o direito vigente, nas leis internacionais e nacionais, e a moralidade comum. Por isso, crê-se que o respeito e a proteção ao direito à vida e à saúde sejam obrigações morais e legais simples de serem cumpridas; todavia, "ao contrário, é terrivelmente complicado [pois] o consenso geral quanto [aos direitos humanos] induz a crer que tenham um valor absoluto" (BOBBIO, 1992, p. 4), que, de fato, não tem. A expressão tão genérica, abrangente e heterogênea desses direitos permite uma relativização que traz dificuldades teóricas e práticas, no momento de sua realização, de diversas ordens: filosóficas, políticas, jurídicas, sociais, econômicas, culturais e técnico-científicas. As dificuldades de se articular esses elementos e estabelecer os acordos necessários sobre o conteúdo e o modo de garanti-los têm sido o distanciamento entre o direito vigente na lei e o direito vivido na prática por milhões de pessoas, em todo o mundo.

A alta intensidade da demanda judicial no âmbito da saúde reflete essa busca de aproximação, ou melhor, de efetividade de um aspecto desse direito, que é o acesso aos meios materiais para seu alcance. No caso do Brasil, o Estado é o 
principal responsável e cumula deveres legais de proteção da saúde, no âmbito individual e coletivo, e de prover os meios para o cuidado de todos os cidadãos.

Os estudos sobre o fenômeno da judicialização no Brasil revelam algumas deficiências e insuficiências do sistema de saúde e judicial brasileiro para responder de forma satisfatória suas responsabilidades sanitárias (SANT'ANA, 2009; ROMERO, 2008; MARQUES; DALLARI, 2007; BORGES, 2007; VIEIRA; ZUCCHI, 2007). Os trabalhos empíricos apontam que a demanda judicial brasileira mais recorrente no âmbito da saúde é constituída por pedidos - individuais e coletivos - de medicamentos. Os pedidos judiciais se respaldam numa prescrição médica e na suposta urgência de obter aquele insumo, ou de realizar um exame diagnóstico ou procedimento, considerados capazes de solucionar determinada "necessidade" ou "problema de saúde". A escolha da via judicial para o pedido pode ser dar pela pressão para a incorporação do medicamento/procedimento no SUS ou pela ausência ou deficiência da prestação estatal na rede de serviços públicos. Nesta última situação, pode-se dizer que a judicialização da saúde expressa problemas de acesso à saúde em seu sentido mais genérico, isto é, como uma dimensão do desempenho dos sistemas de saúde associada à oferta (TRAVASSOS; MARTINS, 2004), e que o fenômeno pode ser considerado como um recurso legítimo para a redução do distanciamento entre direito vigente e o direito vivido.

A resposta judicial, em geral, tem-se limitado a determinar o cumprimento pelos gestores de saúde da prestação requerida pelos reivindicantes, respaldados por uma prescrição médica individual. Porém, nem sempre o insumo ou procedimento requerido é concordante com Protocolos Clínicos e Diretrizes Terapêuticas (PCDT) estabelecidos pelas instâncias do SUS, ou está incluído nas listas de medicamentos financiados pelo sistema público (SANT'ANA, 2009; ROMERO, 2008; MARQUES; DALLARI, 2007; BORGES, 2007; VIEIRA; ZUCCHI,, 2007, MESSEDER et al., 2005). Tal posicionamento do Judiciário tem resultado em uma forte tensão e discussão sobre a legitimidade e a competência técnica e/ou legal-institucional do poder judicial, para decidir sobre o conteúdo e o modo como a prestação estatal deve ser cumprida pelo Executivo da Saúde . Esta deliberação, a princípio, é de competência dos Poderes Executivos em conjunto com as instâncias deliberativas da gestão administrativa do SUS, considerando as implicações orçamentárias e técnicas que envolvem a incorporação de tecnologias - em especial, as novas tecnologias - na assistência à saúde individual e coletiva. 
Há um relativo consenso sobre a possibilidade de se exigir judicialmente do administrador a implementação das políticas públicas, ou mesmo sua adequação às diretrizes, princípios e conteúdos determinados na Constituição Federal e leis infraconstitucionais. Porém, são muitas as dúvidas e divergências sobre como as prestações genéricas devem ser cumpridas especificamente pelo Estado, quais os limites e os meios legais e eticamente válidos de exigi-las, se não forem cumpridas.

De fato, observa-se que a demanda judicial evidencia uma tensão interna no sistema de assistência à saúde, entre a autonomia do médico em sua prescrição à pessoa atendida (mesmo aqueles funcionários do sistema público de saúde) e os regulamentos, normas sanitárias, PCDTs. No sistema legal brasileiro, o profissional médico é responsável pessoalmente pelos danos ou "perda de chance de cura” (ROSÁRIO, 2008) que causar ao paciente. Da mesma forma, o ente público também pode ser responsabilizado. Mas as responsabilidades pessoais e institucionais são diferenciadas tanto na perspectiva legal como na dimensão ética. A responsabilidade dos profissionais de saúde é analisada de forma subjetiva, o reclamante deve comprovar que o profissional não agiu conforme as boas práticas médicas e que cometeu algum erro, imperícia ou negligência que lhe causou o dano. A obrigação do Estado é objetiva, pois o reivindicante deve apenas comprovar a relação causal efetiva entre a omissão/ação do ente público e o dano reclamado pelo cidadão. Para ilidir sua culpa, o Estado que deve comprovar que o referido dano não poderia ter sido evitado ou minimizado.

No debate jurídico atual, há três posições sobre a eficácia do direito à saúde, que se desdobram em análises acerca das possibilidades de atuação do Judiciário na determinação de prestações a serem cumpridas pelo SUS.

1. Uma primeira posição entende que a eficácia desse direito deve ser restrita aos serviços e insumos disponíveis do SUS, determinados pelo gestor público.

2. Uma segunda compreende que o direito à saúde implica garantia do direito à vida e integridade física do indivíduo, devendo o Judiciário considerar a autoridade absoluta do médico que assiste ao autor da ação judicial, obrigando o SUS a fornecer o tratamento indicado.

3. Uma terceira posição defende que a eficácia do direito à saúde necessita ser a mais ampla possível, devendo o Judiciário - na análise do caso concreto - ponderar direitos, bens e interesses em jogo, para fixar o conteúdo da prestação devida pelo Estado. 
A terceira posição é a que se revela mais adequada à compreensão da sinergia entre saúde e direito, na garantia do cidadão ao acesso à justiça e acesso à saúde (LEIVAS, 2006). O juiz deverá levar em conta, por exemplo, se as alternativas terapêuticas, oferecidas pelo SUS, podem atender às necessidades do demandante, sem prejuízos significativos para seu bem-estar; ou se a prescrição médica individual requerida, comparada ao que há disponível no SUS e respaldada por evidências científicas, é o único meio eficiente para garantir a saúde do demandante.

Esta alternativa também pode ser favorável à própria redução da demanda judicial, considerando, por exemplo, que esta pode diminuir quando os PCDTs são atualizados com mais rapidez e quando há distribuição regular de determinada terapia. Esta parece ter sido uma resposta estatal eficiente para redução da demanda judicial no caso da Aids, que representava 90\% da demanda entre 1991 a 1998, passando para $16,7 \%$ no ano de 1999 , e $14,6 \%$ no ano de 2000 (MESSEDER et al., 2005). Em estudos mais recentes no Rio de Janeiro, a demanda relacionada ao HIV/Aids continua muito baixa, inferior a 5\% (BORGES, 2007; SANT’ANA, 2009). Até o momento, mesmo os estudos que enfatizam os aspectos negativos da ampliação da atuação judicial no sistema de saúde reconhecem que há, de fato, um descompasso entre a oferta e a demanda do cidadão no sistema público, e um atraso na incorporação de novas tecnologias no sistema público de saúde, que se expressa, no contexto brasileiro, na crescente demanda judicial. Uma das principais divergências identificadas na discussão está relacionada ao modo como uma sociedade democrática deve solucionar este déficit entre demanda e oferta de novas tecnologias, considerando a escassez de recursos e sua justa distribuição.

Em relação à incorporação de novas tecnologias no SUS, constata-se não só o regular atraso como o fato de que ela é feita, por vezes, de forma acrítica, podendo comprometer não apenas a qualidade da prestação de serviços, mas também a equidade (RIBEIRO, 2002). Destaca-se, ainda, que "não existe uma correspondência simples entre saber técnico-científico e saber moral" (SCHRAMM; ESCOSTEGUY, 2000, p. 954), isto é, que a incorporação das novas tecnologias na prática médica e nos sistemas de saúde deve levar em conta não só "objetivos pragmáticos dos gestores na avaliação da eficiência, eficácia e efetividade das novas tecnologias" (SCHRAMM, 2007, p. 9), mas também os 
deveres éticos e legais de proteção e cuidado, que maximize benefícios e reduza malefícios, preserve as liberdades individuais e o acesso igualitário aos bens públicos. Nesse sentido, recomenda-se que os poderes públicos fortaleçam e/ou criem instâncias institucionais consistentes que atendam às exigências políticas, éticas, legais e científicas, que requer o processo regulatório das novas tecnologias, em especial, os critérios de inclusão e exclusão dos sujeitos de direitos. A ampla transparência e a participação dos diversos atores sociais nesse processo regulatório é que poderão legitimar as restrições absolutamente necessárias.

Conclui-se que o direito à saúde possui dimensōes éticas, políticas, jurídicas e técnico-científicas indissociáveis, e sua maior ou menor realização dependerá de um diálogo de interação aberta orientado por um enfoque hermenêutico, no plano individual ou coletivo, aliado ao enfrentamento de desafios teóricos e práticos na construção das novas instrumentalidades para sua efetividade (AYRES, 2007). Compreender como vêm se dando as relações e os diálogos entre essas dimensões na produção da base normativa que orienta leis, políticas e práticas de saúde é um passo importante em prol da efetividade do direito à saúde ou, ao menos, para ampliação do acesso à justiça e à saúde.

\section{Acesso à justiça e fornecimento de medicamentos no Município do Rio de Janeiro}

Como estratégia para a melhor compreensão do fenômeno da judicialização da saúde, encontra-se em andamento a pesquisa sobre “Judicialização e Saúde Pública: proposta de análise e monitoramento das demandas judiciais individuais para o acesso a medicamentos", aprovada pelo Comitê de Ética em Pesquisa da Escola Nacional de Saúde Pública Sergio Arouca, Fundação Oswaldo Cruz (Parecer n. ${ }^{\circ}$ 105/08 CAAE: 0131.0.031.000-08).

A pesquisa está sendo realizada a partir da base de dados cedida pelo Tribunal de Justiça do Estado do Rio de Janeiro (TJ/RJ), referente à distribuição processual - ato que o reivindicante protocoliza seu pedido no Tribunal de Justiça, dando início à demanda judicial dos pedidos individuais de fornecimento de medicamentos tendo o Estado do Rio de Janeiro como réu. No período de julho de 2007 a junho de 2008, foram identificados 1.263 processos judiciais na Comarca da Capital, que corresponde à área territorial do Município do Rio de 
Janeiro, e analisados os atos processuais disponíveis, em amostra aleatória simples de 289 processos judiciais.

O estudo busca combinar, numa perspectiva interdisciplinar, abordagens de análise quantitativa e qualitativa. Seu objetivo geral é identificar variáveis no banco de dados do Poder Judiciário que possam evidenciar características dos demandantes e da demanda judicial, e permitam análises atuais e rápidas das partes envolvidas, das estratégias por elas adotadas e o padrão de resposta do Judiciário local. Para este artigo, foram analisadas duas variáveis: (1) se o demandante é beneficiário da gratuidade de justiça e (2) se houve decisão judicial antecipatória da tutela (liminar).

(1) Na primeira variável, verificou-se se o autor requereu e obteve o benefício da gratuidade de Justiça. Este benefício legal depende da caracterização da hipossuficiência econômica do autor processual, nos termos do art. $2^{\circ}$, p. único, da Lei no 1.060/50, que exige que o reivindicante comprove não possuir condições de arcar com as despesas processuais e advocatícias, sem prejuízo de seu sustento e de sua família. Os beneficiários da gratuidade de justiça são representados por advogados dativos ou por defensores públicos estatais. Esta variável permite evidenciar, mesmo que timidamente, uma característica pessoal do demandante, bem como a correlação entre acesso à justiça e a efetividade do acesso a medicamentos, considerando o tipo de processos judiciais analisado.

Em relação ao acesso à justiça, é importante ressaltar que o Estado democrático de direito pressupõe a existência de canais sólidos de exercício do direito de ação via Poder Judiciário, caso o cidadão entenda que houve lesão ou ameaça de violação a algum direito. E, para o exercício deste direito, a concessão da gratuidade de justiça significa, por inúmeras vezes, sua própria viabilidade, especialmente diante de uma população empobrecida. Assim, a assistência jurídica gratuita oferecida pelas Defensorias Públicas dos estados constitui, tal qual o direito à saúde, um direito fundamental do cidadão e um dever do Estado previstos constitucionalmente, e representa uma das conquistas no acesso da população ao Judiciário.

No mesmo sentido de aumentar a efetividade do direito à saúde, a Constituição Federal e a Lei Federal n. ${ }^{\circ}$ 8.080/90 estabelecem o acesso 
gratuito e igualitário ao sistema público de saúde. A diferença é que, no SUS, a gratuidade é pressuposto do acesso, enquanto que, no sistema justiça, a gratuidade não é regra e somente será concedida se houver comprovação da necessidade econômica do autor, podendo inclusive ser impugnada pela parte contrária. Isto implica que o autor, para se beneficiar da gratuidade, deve comprovar sua impossibilidade de arcar com as despesas processuais da ação judicial, ou seja, sua hipossuficiência econômica, mas não necessariamente lhe é exigido demonstrar a impossibilidade de arcar com os custos do insumo e/ou do procedimento de saúde requeridos.

A tabela 1, a seguir, revela que não foi encontrado, no âmbito da pesquisa em curso, nenhum processo em que tenha sido negada a gratuidade de justiça.

Tabela 1 - Distribuição das açôes individuais de medicamentos, segundo hipossuficiência econômica do autor. Comarca da Capital do RJ. Estado do RJ, julho/07 a junho/08.

\begin{tabular}{l|c|c}
\hline \multicolumn{1}{c|}{ Hipossuficiência econômica } & N & Percentual (\%) \\
\hline $\begin{array}{l}\text { Indica hipossuficiência econômica do autor (concede } \\
\text { gratuidade de justiça ou menciona a Defensoria Pública) }\end{array}$ & 277 & 95,8 \\
\hline Negado pedido de gratuidade de justiça & 0 & 0 \\
\hline Não menciona hipossuficiência econômica do autor & 12 & $4,2^{* *}$ \\
\hline Total & 289 & 100 \\
\hline
\end{tabular}

Fonte: TJ/RJ. Elaboração própria.

** A insuficiência na transcrição dos dados no banco do TJ/RJ significou uma pequena perda na análise da amostra.

O dado analisado permitiu constatar que solicitação e deferimento da gratuidade de justiça e, consequentemente, o reconhecimento judicial da hipossuficiência econômica do reivindicante, é uma característica majoritária da demanda judicial de medicamentos. Mesmo considerando que as normas legais de acesso gratuito são diferenciadas nos sistemas de justiça e de saúde, podese inferir que o reivindicante também não possui condições para arcar com os 
custos de seu tratamento, considerando que as despesas judiciais em geral são pontuais e bem menores do que as despesas com alguns tratamentos de saúde. Neste sentido, a alta intensidade deste tipo de demanda não permite afirmar que ela, necessariamente, viole a equidade no acesso à saúde, mas aponta que tem favorecido o acesso ao sistema público de cidadãos sem condições de arcar com os custos de seus medicamentos e da demanda judicial - conquanto esta característica majoritária da demanda judicial possa ser problematizada no estabelecimento de critérios para o alcance da equidade no acesso à saúde.

(2) Uma segunda variável importante para esboçar o padrão da resposta do Judiciário a essas demandas é se houve, ou não, pedido de antecipação da tutela judicial, comumente chamada de "pedido de liminar". A antecipação de tutela é um tipo de decisão judicial na qual o Juiz, baseado em provas apresentadas pelo reivindicante, deve avaliar se o "perigo da demora" do procedimento judicial, necessário para o julgamento do processo, pode resultar em violação irreparável do direito do autor do processo, p.ex., agravamento de seu estado de saúde. Um segundo elemento necessário para a apreciação judicial é se há "fumaça do bom direito", isto é, se o juiz também verifica, mesmo em caráter provisório, se o pedido está amparado por lei. Após a concessão da "liminar", o procedimento continuará e, caso o juiz, ao final, verifique que a prestação solicitada não era devida, o autor deve indenizar o réu. Este, por sua vez, pode se insurgir contra a antecipação de tutela deferida, apresentando provas contrárias à pretensão do requerente. A tutela antecipada, então, poderá ser revista pelo próprio juiz que a concedeu, ou por instâncias colegiadas superiores. A antecipação da tutela judicial é ato de caráter excepcional na lei processual brasileira, mas é relevante notar que no âmbito da demanda judicial de saúde tem-se transformado em ato de rotina, com significados e efeitos amplos para a efetividade do direito à saúde no Brasil.

Observa-se que, em todos os processos da amostra selecionada, houve pedido de antecipação da tutela judicial, e em 100\% dos casos ela foi concedida. A tabela 2 , a seguir, explicita inclusive que em $20 \%$ dos processos o juiz determinou liminarmente o fornecimento de outros medicamentos necessários ao tratamento do requerente, além dos requeridos na petição inicial, desde que comprovados com prescrição médica. 
Tabela 2 - Distribuição das açóes individuais de medicamentos, segundo apreciação dos pedidos de tutela antecipada. Comarca da Capital do RJ. Estado do RJ, jullho/07 a junho/08

\begin{tabular}{|l|c|c|}
\hline \multicolumn{1}{|c|}{ Apreciação dos pedidos de tutela antecipada } & N & Percentual (\%) \\
\hline $\begin{array}{l}\text { Foi concedida a tutela antecipada, integralmente, para } \\
\text { fornecimento dos medicamentos solicitados. }\end{array}$ & 227 & 78,5 \\
\hline $\begin{array}{l}\text { Foi concedida a tutela antecipada, integralmente, para } \\
\text { "fornecimento dos medicamentos solicitados, ou outros } \\
\text { necessários a seu tratamento, desde que comprovada a } \\
\text { prescrição médica". }\end{array}$ & 53 & 18,3 \\
\hline $\begin{array}{l}\text { Foi concedida a tutela antecipada, integralmente, para } \\
\text { "fornecimento dos medicamentos solicitados ou outros } \\
\text { necessários a seu tratamento, desde que comprovada a } \\
\text { prescrição médica oriunda do SUS". }\end{array}$ & 5 & 1,7 \\
\hline Foi concedida PARCIALMENTE a tutela antecipada. & $4^{*}$ & 1,4 \\
\hline Não foi concedida a tutela antecipada. & 0 & 0,0 \\
\hline Total & 289 & 100 \\
\hline
\end{tabular}

Fonte: TJ/RJ. Elaboração própria.

* Nestes casos, não há descrição do conteúdo do pedido negado.

Constata-se que o principal critério judicial para a concessão da tutela é a constatação da necessidade do autor de acesso urgente a determinado medicamento ou procedimento prescrito pelo médico que o assistiu. Neste sentido, o respaldo das decisões judiciais é constituído precipuamente por documentos fornecidos pelo paciente-demandante, que expressam essa necessidade - em geral, em atestados e/ou receituários médicos.

Aprofundando a análise dessa variável - concessão da tutela antecipada constata-se, na tabela 3, que, em $96,9 \%$ das decisões, o juiz não fez nenhuma exigência para a concessão ou manutenção do pedido liminar, firmando sua convicção somente na documentação apresentada pelo reivindicante. O resultado evidencia a soberania da prescrição médica individual e a não-relativização de seu conteúdo com regulamentos e normas sanitárias, ou outros meios de prova 
que constate se a prescrição é adequada; por exemplo: por meio de um parecer

técnico que possa esclarecer a existência de alternativa terapêutica mais adequada ao caso, a urgência no acesso ao medicamento, ou mesmo se esse medicamento é padronizado para fornecimento no SUS.

Tabela 3 - Distribuição das ações individuais de medicamentos, segundo exigências. Comarca da Capital do RJ. Estado do RJ, jullho/07 a junho/08

\begin{tabular}{|l|c|c|}
\hline \multicolumn{1}{|c|}{ Exigências } & N & Percentual (\%) \\
\hline $\begin{array}{l}\text { O juiz NÃO solicitou nenhuma exigência, valendo-se da } \\
\text { documentação acostada na petição inicial. }\end{array}$ & 280 & 96,9 \\
\hline $\begin{array}{l}\text { O juiz solicitou declaração ou atestado médico, } \\
\text { originado do SUS. }\end{array}$ & 5 & 1,8 \\
\hline O juiz solicitou laudo médico, originado do SUS. ${ }^{1}$ & 3 & 1,0 \\
\hline O juiz solicitou exigência de outra natureza. & & 0,3 \\
\hline Total & 289 & 100 \\
\hline
\end{tabular}

Fonte: TJ/RJ. Elaboração própria.

1. Em um único caso, o juiz solicitou mais informaçôes: "Venha laudo e receituário justificando a necessidade dos medicamentos pleiteados elaborado por médico de unidade pública de saúde."

2. Neste caso, o juiz solicitou os documentos originais (presume-se que sejam os receituários médicos).

Em geral, os estudos sobre as ações judiciais para o acesso a medicamentos e procedimentos de saúde apontam que a fragilidade no conteúdo das decisões pode estar relacionada ao desconhecimento que tem o sistema de justiça Poder Judiciário, Defensoria Pública, Ministério Público e advogados - sobre os argumentos e regulamentos da saúde pública; em especial, ao uso racional de medicamentos na perspectiva da proteção e segurança do paciente, e os problemas referentes às prescrições médicas que não atendem às exigências de segurança e eficácia necessárias ao tratamento da pessoa, como referido anteriormente.

Os dados acima, relacionados à soberania da prescrição médica individual e à não-relativização de seu conteúdo na perspectiva da saúde pública, corroboram os demais estudos, embora se constate a necessidade de ampliar as análises, buscandose compreender em que medida esse fenômeno revela especificidades relacionadas 
ao uso do sistema de justiça pela população carente. Essas análises constituem fonte de informações valiosas para a formulação de estratégias de intervenção, notadamente para gestores de saúde nos contextos locais. Por exemplo, com base nos dados parciais da pesquisa apresentada, pode-se inferir que a assistência jurídica gratuita e, em especial, a atuação da Defensoria Pública do Estado, tem sido um elo importante na garantia do acesso à saúde ou, mais restritamente, ao uso de serviços do SUS, na cidade do Rio de Janeiro. Apontam também como o debate da judicialização da saúde revela, de forma privilegiada, as tensões dos conceitos de saúde e doença, bem como as possibilidades de diálogo entre diversos campos.

\section{Considerações finais}

A lei constitucional admite que qualquer cidadão que se sinta ameaçado ou lesado, em razão da não-inclusão de um medicamento mais adequado para sua terapia no protocolo terapêutico, pode ingressar com ação judicial, individual ou coletiva, requerendo o exame judicial do conflito. Todavia, é certo também que a lei exige o exame judicial com base não apenas na lei, ou na Constituição, mas considerando todos os demais elementos indicados pelo gestor que justifique a não-incorporação do medicamento em questão.. Avalia-se, portanto, se o ato que restringe a liberdade do cidadão é razoável e não lhe causará dano.

Assim, o conceito de acesso à justiça não se limita apenas ao ingresso formal do paciente com um processo judicial e a concessão, pura e simplesmente, de um pedido do cidadão, mas significa a garantia de uma solução justa, no sentido de produzir uma adequada prestação jurisdicional. No caso em análise, espera-se a resolução do conflito, garantindo-se materialmente o resguardo do direito à saúde dos cidadãos, com o fornecimento do medicamento necessário, seguro e eficaz para seu tratamento de saúde. Portanto, o acesso à justiça aqui é considerado de forma mais ampla, como o acesso aos benefícios jurídicos em geral no nível legislativo e administrativo, além do acesso ao Judiciário. De fato, há grande dificuldade de se estabelecer um consenso entre as partes envolvidas e/ ou afetadas pelas decisões judiciais nesse âmbito, porque implica decidir sobre o que é justo se reivindicar e o que se deve proteger, a partir da abstração do que é justo e do pluralismo moral existente nas sociedades democráticas.

Contamos, ainda, com a dificuldade de estabelecer a coerência entre o direito vigente e o direito vivido. Ou seja, o direito vigente, que reconhece o direito à 
saúde de forma universal, integral e gratuita, como uma lei justa. E o direito vivido, que aponta violações diárias decorrentes das profundas desigualdades sociais e pessoais, combinadas com as deficiências dos sistemas públicos de saúde, que espelham a incapacidade do Estado (ou a ausência de vontade política) de atender às necessidades dos cidadãos.

A emergência de novos atores sociais, com reivindicações e focos de atuação nas diversas instâncias de elaboração das políticas públicas, é uma forte característica da sociedade brasileira contemporânea. Este modelo participativo, corolário do princípio democrático, produz efeitos nos poderes instituídos. O princípio democrático, relacionado ao exercício do direito político, passa a enfatizar, mais recentemente, a necessidade de que seja assegurada a ativa participação e consideração dos interesses de todos os sujeitos de direito, também no processo de identificação de prioridades na tomada de decisões, no planejamento, na implementação e na avaliação das políticas públicas, e não simplesmente na eleição de representantes na instância legislativa e chefes dos Poderes Executivos. Nesse sentido, um dos mecanismos construídos nas últimas décadas foi a potencialização do conflito social no âmbito do Judiciário, como estratégia legítima para a defesa, promoção e garantia de direitos.

A nova ordem constitucional permite a atuação do indivíduo como sujeito ativo de direitos, e não um mero alvo de políticas estatais ou portador de necessidades a serem moralmente concedidas. O Estado é indicado como principal responsável pelo cumprimento das obrigações legais de forma universal, igualitária e democrática, de modo a atender efetivamente aos interesses reais de toda a população.

O fortalecimento destes mecanismos de controle do poder estatal e de prestação de contas passa a integrar a própria estrutura de garantia dos direitos humanos, sob a ótica de que a legitimidade do poder político não está restrita à representatividade, mas está igual e diretamente relacionada à transparência e accountability no que se refere às políticas públicas. Neste sentido, a ampliação do poder judicial, com a consequente judicialização da política, não pode ser analisada de maneira pontual e isolada, mas, sim, como um fenômeno situado historicamente no processo de construção democrática da sociedade brasileira, e potencialmente favorável à ampliação dos mecanismos de participação e garantia de direitos. A identificação do Judiciário como arena de embate - onde se garante formalmente a igualdade com o contraditório e a ampla defesa - é uma resposta 
à insuficiência ou deficiências dos canais institucionais tradicionais de controle social e de participação popular.

A construção normativa de uma sociedade pressupõe o conflito de interesses e, do mesmo modo, a demanda judicial reflete disputas, conquistas ou retrocessos, estabelecidos para além da esfera jurídica. O grande desafio é pensar na judicialização da saúde como estratégia legítima, porém a ser orquestrada com outros mecanismos de garantia constitucional de saúde para todos. As demandas judiciais não podem ser consideradas como principal instrumento deliberativo, pois, de fato, para o alcance da justiça, deve ser adotado um conjunto de ações por meio das quais se busque implementar as diretrizes constitucionais.

As discussões sobre os limites e possibilidades da intervenção do Judiciário não se restringem à análise do conteúdo da decisão judicial ao regulamento ou à prescrição médica adequada, mas colocam em jogo novos atores na partilha de poderes e renomeação de domínios. A resistência de se admitir como legítima esta intervenção repousa, em razão das deficiências da atuação judicial nesse novo campo, mais nas dificuldades políticas de se implementar a democracia ampliada e participativa, do que em debilidades operacionais superáveis, com relação às quais os gestores dos dois sistemas vêm avançando (PEPE et al., 2008).

De fato, a judicialização da saúde traz alterações significativas nas relações sociais e institucionais, com desafios para a gestão e para os diversos campos do saber-fazer, representando efetivamente o exercício da cidadania plena e a adequação da expressão jurídica às novas e crescentes exigências sociais.

Agradecemos o financiamento da Secretaria de Ciência e Tecnologia e Insumos Estratégicos do Ministério da Saúde, relativo à pesquisa dos processos judiciais; às pesquisadoras integrantes da equipe, Claudia Garcia Serpa Osorio-de-Castro e Tatiana Aragão Figueiredo, por suas contribuiçōes no projeto, e a colaboração das Sras. Guacira Duarte Soares e Maria Elisa Vidal Bernardo, funcionárias do Tribunal de Justiça do Estado do Rio de Janeiro TJ/RJ, na disponibilização e auxílio na coleta dos dados.

Colaboradores: Miriam Ventura realizou a busca bibliográfica, discussão e redação do artigo. Luciana Simas realizou a análise das decisōes judiciais, discussão e redação do artigo em conjunto com a primeira autora. Vera Lúcia E. Pepe coordena a pesquisa empirica e contribuiu com a discussão e revisão do artigo de forma crítica e relevante. Fermin $\boldsymbol{R}$. Schramm contribuiu com a discussão e a revisão do artigo de forma crítica e relevante, e na orientação da primeira autora. 


\section{Referências}

AYRES, J.R.C.M. Uma concepção hermenêutica de saúde. Physis, Rio de Janeiro, v. 17, n. 1, p. 43-62, 2007. Disponível em: <http://www.scielo.br/physis.

BAPTISTA, T.W.F.; MACHADO, C.V.; LIMA, L.D. Responsabilidade do Estado e direito à saúde no Brasil: um balanço da atuação dos Poderes. Ciência \& Saúde Coletiva, v. 14, n. 3, p. 829-839, 2009.

BARATA, R.; CHIEFFI, A.L. Judicialização da política pública de assistência farmacêutica e equidade, Cad. Saúde Pública, Rio de Janeiro, 25(8):1839-1849, ago, 2009.

BARROSO, L.R. Da falta de efetividade à judicialização excessiva: direito à saúde, fornecimento gratuito de medicamentos e parâmetros para a atuação judicial. Revista de Direito da Procuradoria Geral do Estado do Rio de Janeiro. Disponível em: http://www.pge.rj.gov.br/ sumario_rev63.asp. Acessado em: 25 out. 2009.

BOBBIO, N. A era dos direitos. Rio de Janeiro: Campus, 1992.

BORGES, D.L.C. Uma análise das açôes judiciais para o fornecimento de medicamentos no âmbito do SUS: o caso do Estado do Rio de Janeiro no ano de 2005. Dissertação (Mestrado em Saúde Pública) - Escola Nacional de Saúde Pública, Fundação Oswaldo Cruz, Rio de Janeiro, 2007.

BRASIL. Ministério da Saúde. OPAS/OMS. Avaliação da Assistência Farmacêutica no Brasil: estrutura, processo e resultados. Brasília, 2005 (Série Medicamentos e Outros Insumos Essenciais para a Saúde). 260p.

CAMARGO JUNIOR, K.R. As armadilhas da "concepção positiva de saúde". Physis, Rio de Janeiro, v. 17, n. 1, 2007. Disponível em: <http://www.scielo.br/scielo.

ENGELHARDT JR, H.T. Fundamentos da Bioética. São Paulo: Loyola, 1998.

GERHARDT, T.E. Itinerários terapêuticos em situações de pobreza: diversidade e pluralidade. Cad. Saúde Pública, Rio de Janeiro, v. 22, n. 11, p. 2.449-2.463, 2006.

INSTITUTO BRASILEIRO DE GEOGRAFIA ESTATÍSTICA. Pesquisa de orçamentos familiares 2002-2003. Rio de Janeiro: 2004.

INSTITUTO BRASILEIRO DE GEOGRAFIA ESTATÍSTICA (IBGE). Pesquisa Nacional por amostras de Domicílios 1998. Rio de Janeiro, 1998.

LEFÈVRE, Fernando. A oferta e a procura de saúde através do medicamento: proposta de um campo de pesquisa. Rev. Saúde Pública, São Paulo, v. 21, n. 1, fev. 1987. Disponível em: $<$ http://www.scielo.br/scielo.

LEIVAS, P.G.C. Princípios de direito e de justiça na distribuição de recursos escassos. Revista Bioética, vol. 14, n. 1, 2006, Brasília: Conselho Federal de Medicina, 2006.

LOYOLA, M.A. Medicamentos e saúde pública em tempos de Aids: metamorfoses de uma política dependente. Ciênc. Saúde Coletiva [online]. 2008, v. 13, suppl., p. 763-778. 
MARQUES, S. B.; DALLARI, S.G. Garantia do direito social à assistência farmacêutica no Estado de São Paulo. Brasil. Rev. Saúde Pública, v. 41, n. 1, p. 101-107, 2007.

MESSEDER, A.M.; OSORIO-DE-CASTRO, C.G.S.; LUIZA, V.L. Mandados judiciais como ferramenta para garantia do acesso a medicamentos no setor público: a experiência do Estado do Rio de Janeiro, Brasil. Cad. Saúde Pública, v. 21, n. 2, p. 525-534, 2005.

PEPE, V.L.E. et al. Relatório do Seminário Nacional Gestão e Monitoramento das Ações Judiciais de Medicamento - Projeto de Cooperação Ensp / Sesdec-RJ - subprojeto judicialização - Fiocruz, Julho, 2008. Disponível em: http://chagas2.redefiocruz.fiocruz.br/drupalsesdec/files/Relat\%C3\%B3rio_do_Semin\%C3\%A1rio_Nacional_Judiciali.pdf

RIBEIRO, C.D.M. Os que nascem em processo de morrer e outros recém-nascidos. Escolhas trágicas no início da vida: 'Cultura dos limites', Justiça sanitária e alocação de recursos: argumentações racionais acerca dos conflitos morais em medicina intensiva neonatal, do ponto de vista dos profissionais intensivistas. Tese (Doutorado) - Escola Nacional de Saúde Pública, Fiocruz, Rio de Janeiro, 2002.

RIOS, R.R. Respostas jurídicas frente à epidemia de HIV/Aids no Brasil. Divulgação em Saúde para Debate. CEBES, Rio de Janeiro, n. 27, p. 95-106, agosto 2003.

ROMERO, L.C. Judicialização das políticas de assistência farmacêutica: o caso do Distrito Federal. Brasília: Consultoria Legislativa do Senado Federal, 2008 (Textos para discussão 41).

ROSÁRIO, G.C.M.. A perda da chance de cura na responsabilidade médica. Revista da EMERJ, v. 11, n. 43, Rio de Janeiro, 2008.

SANT'ANA, J.M.B. Essencialidade e Assistência Farmacêutica: um estudo exploratório das demandas judiciais individuais para acesso a medicamentos no estado do Rio de Janeiro. Dissertação (Mestrado em Saúde Pública) - Escola Nacional de Saúde Pública, Fiocruz, Rio de Janeiro, 2009.

SCHEFFER, M.; SALAZAR, A.L.; GROU, K.B. O Remédio via Justiça: um estudo sobre o acesso a novos medicamentos e exams em HIV/AIDS no Brasil por meio de ações judiciais. Brasília: Ministério da Saúde, 2005 (Série Legislação n. 3).

SCHRAMM, F.R.; ESCOSTEGUY, C.C. Bioética e avaliação tecnológica em saúde. Cad. Saúde Pública [online]. 2000, v. 16, n. 4, p. 951-961.

SCHRAMM, F.R. Bioética da proteção e incorporação de C\&T em saúde. BIS - Boletim do Instituto de Saúde, n. 42, ago. 2007.

SCLIAR, M. História do conceito de saúde. Physis, Rio de Janeiro, v. 17, n. 1, 2007. Disponível em: <http://www.scielo.br/scielo.

SZWARCWALD, C.L. et al. Pesquisa Mundial de Saúde 2003: O Brasil em números. Revista Radis, v. 23, p. 14-33, 2004. Disponível http://www4.ensp.fiocruz.br/radis/23. 
TRAVASSOS, C.; MARTINS, M. Uma revisão sobre os conceitos de acesso e utilização de serviços de saúde. Cad. Saúde Pública, Rio de Janeiro, v. 20, sup. 2, p.190-198, 2004.

VENTURA, M. As estratégias de promoção e garantia dos direitos das pessoas que vivem com HIV/Aids. Divulgação em Saúde para Debate. Rio de Janeiro, n. 27, p. 107-115, agosto 2003 .

VIANNA, L.W.; BURGOS, M.B. Entre princípios e regras (cinco estudos de caso de Ação Civil Pública), Cadernos CEDES-IUPERJ, p. 1-47, jan. 2005.

VIEIRA, F.S.; ZUCCHI, P. Distorções causadas pelas ações judiciais à política de medicamentos no Brasil. Rev. Saúde Pública, v. 41, n. 2, p. 214-222, 2007. 
Judicialization of the right to health, access to justice and the effectiveness of the right to health This paper aims to analyze the links between access to justice and the effectiveness of one aspect of the right to health: access to medicines. It initially presents the challenges and difficulties in the conceptualization of health and right to health, and then analyzes individual lawsuits demanding medicines against public services, from June 2007 to July 2008, entered at Rio de Janeiro State Court of Appeals. It appears that the medical drug prescription, the economic conditions of the applicants and the urgency of access to medicines are the main factual basis of judicial sentences examined, which determine the supply of medicines as required by the authors. Finally, it concludes that the effectiveness of the right to health requires a set of policy and broader government actions, and not merely formal and restrictive court orders. The individual's claims cannot be considered as the main deliberative instrument in the management of pharmaceutical care in the Brazilian Health System, but accepted as an important element in the decision making of managers and, often, in the improvement of the access to medicines under National Health System. In the Brazilian democratic context, the judicialization can express demands and modes of action of citizens and legitimate institutions. Thus, the main challenge is to make policy and social strategies orchestrated with other mechanisms and instruments of democratic security, to improve health and justice systems in order to give effectiveness to the right to health.

> Key words: right to health, pharmaceutical services, justice administration system, bioethics. 